\section{Brazil invites RGS explorers}

This week the first of 60 scientists depart for Brazil to make the final preparations for the biggest European-led research expedition ever to study an Amazon rainforest. The project team, led by Dr John Hemming, director and secretary of the Royal Geographical Society (RGS), will be based on the island of Maraca close to the watershed between the Amazon and Orinoco basins.

The invitation was made to RGS two years ago by the Brazilian Environmental Secretariat (SEMA), but it has taken since then to organize and raise from a mixture of industrial, private and government sponsors the $£ 125,000$ that will fund the basic needs of the year-long project.

Hemming says "we jumped at the invitation since, although Brazil contains almest two thirds of the world's surviving rainforests, it is difficult for foreign scientists to obtain permission to work there."

Half of the teams will come from the United Kingdom with Brazil making up most of the remainder. Maraca, an uninhabited island $60 \mathrm{~km}$ by $25 \mathrm{~km}$, is covered in forest, contains a lake and has swamps and seasonally flooded areas. As a result of the expedition, SEMA, whose permanent research station on Maraca is at the disposal of the RGS team, will acquire a complete survey of the island, including an inventory of the animals, insects and plants, to help plan future research.

RGS says its five research programmes

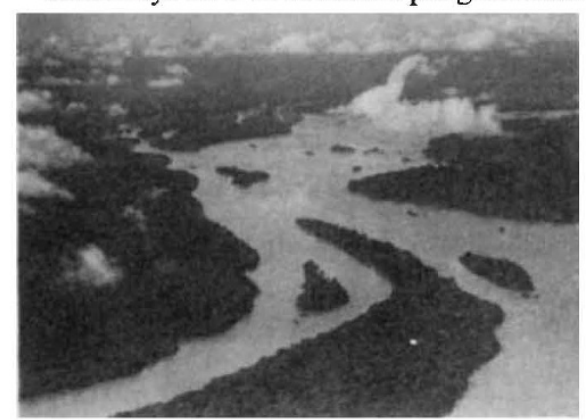

Caracarahy rapids, Rio Branco

have "been welcomed by the Brazilian authorities because of the practical benefit to both farmers and conservationists". They involve an ecological survey, the development of management plans for the reserve, an examination of forest regeneration and the behaviour of soil moisture, a medical-entomological review and a survey of land development.

The Royal Botanic Gardens at Kew in London will oversee the ecological survey which will record, classify and collect hundreds of species of trees, plants, vines and ferns with the help of specialists from the Royal Botanic Garden in Edinburgh and the New York Botanical Garden.

There will be an inventory of hundreds of species of fauna, particularly snakes,

\section{Space shuttle}

frogs, bats, monkeys, insects and birds. Studies of forest regeneration could help restore destroyed areas to their original state. According to RGS, thousands of hectares of rainforest are felled every year for farming, settling, cattle ranching and mining. But a wasteland usually results, claims RGS, and much of it is soon abandoned. Farming proves impossible because of poor soils and intense parasite and weed activity. Once damaged, the rainforests do not regenerate and the research will try to find out why.

Another research programme will in- vestigate how the litter (or debris) on the forest floor is derived from the foliage and decomposes, the dynamics of the rainfall as it drops from the roof or canopy of the forest and the behaviour of that moisture with the soil. Research on endemic tropical diseases will focus on onchocerciasis and leishmaniasis.

The land development survey will study the settlements within reach of the research camp. According to RGS, millions of settlers are moving to the frontiers of the Amazonian forests in a desperate search for land. "This occupation and disturbance often occurs too fast for there to be any planning based on scientific information. As a result, many pioneer colonists fail."

\title{
Money-saving move on fuel tanks
}

\section{Washington}

THE idea of making some use in orbit of each space shuttle's huge external fuel tank is not new, but prospects for its realization may have come closer. Hitherto, the fuel tanks have been allowed to burn up in the atmosphere. But now a new company, External Tanks Corporation, wants to make them into warehouses. The company is seeking private capital to finance what it calls the first private "warehouse in space". The project has the backing of the University Corporation for Atmospheric Research (UCAR), a consortium of 57 major research universities. According to Thomas F. Rogers, chairman of External Tanks Corporation and a former member of NASA's space programme advisory council, the first habitable tank could be in orbit by 1993 .

The shuttle's external tank carries liquid hydrogen fuel and oxygen for the main engines, and is usually jettisoned just before the shuttle reaches orbit. Its diameter is more than the width of a Boeing 747, and its length is equivalent to a 13-storey building. Twenty-four have so far been discarded, each costing $\$ 30$ million. To take the tank into orbit would require only an extra $2,000 \mathrm{lb}$ of fuel, according to Randolph Ware, president of the new company.

The company, which is 80 per cent owned by the UCAR Foundation, a non-profit organization established by UCAR, is seeking capital from "companies that have a long-term strategic interest in the exploitation of the space environment", including hotels. The National Aeronautics and Space Administration (NASA) is apparently taking the company's plan seriously. Several studies have recommended that the idea be investigated, and NASA has now formed a special committee to look at it, chaired by general manager Philip Culbertson.

Culbertson says the "very interesting" idea is "feasible", but adds that NASA has not yet looked into all the technical details and that it would in any event leave the business side to External Tanks Corporation. NASA has some plans of its own for using the tanks: it recently awarded a contract to Martin Marietta Corporation to study turning an external tank into a gamma-ray imaging telescope.

Randolph Ware, president of External Tanks, and Rogers, both of whom have

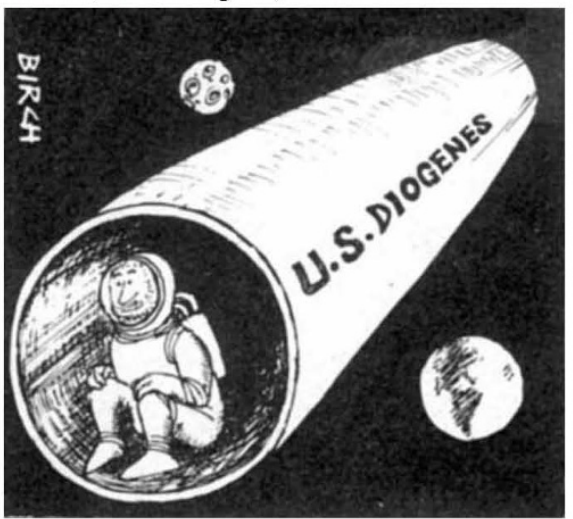

technical backgrounds, say the tanks would need minimal modifications on the ground. Once in orbit, the tank would be detached from the shuttle and fitted with a small thruster that would keep it in stable orbit. Subsequently it would be purged, pressurized and fitted as as "the equivalent of high-cost commercial space", according to Ware, who seems to have no doubts that commercial companies will want to rent.

Among the plans being discussed is one for a fully pressurized permanently inhabited laboratory/factory, Labitat, made from two tanks connected together. The operating cost of Labitat is calculated to be so low that accommodation would cost as little as $\$ 500$ per person per day by the $1990 \mathrm{~s}$, roughly twice the cost of first-class hotel accommodation in the United States. 